\title{
A INFÂNCIA NA NARRATIVA INFANTIL BRASILEIRA: DE MÁRIO A RAQUEL
}

\author{
LA INFANCIA EN LA NARRATIVA INFANTIL BRASILEÑA: DE MARIO A \\ RAQUEL
}

\author{
CHILDHOOD IN BRAZILIAN NARRATIVE FOR CHILDREN: FROM MARIO \\ TO RAQUEL
}

\author{
Flávia BROCCHETTO RAMOS ${ }^{1}$ \\ Eliana RELA ${ }^{2}$
}

RESUMO: Analisar a personagem infantil em cinco obras - Saudade, de Tales de Andrade, Reinações de Narizinho, de Monteiro Lobato, A ilha perdida, Maria José Duprè, A fada que tinha idéias, de Fernanda Lopes de Almeida, e A bolsa amarela, Lygia Bojunga Nunes, é o objetivo deste artigo. O estudo abrange o período de 1919 a 1976 e, além de relacionar a personagem ao contexto histórico de produção de cada uma das narrativas, demonstra como a infância é apresentada em cada história, a fím de refletir acerca do percurso da criança como personagem na literatura infantil brasileira. Por fim, problematiza que a literatura infantil além de ser texto artístico é fonte para o ensino da História no Ensino Fundamental.

PALAVRAS-CHAVE: Narrativa infantil. Personagem. História da literatura infantil brasileira. Ensino de História.

RESUMEN: Analizar el personaje infantil en cinco obras - Saudade, de Tales de Andrade, Reinações de Narizinho, de Monteiro Lobato, A ilha perdida, de Maria José Duprè, A fada que tinha idéias, de Fernanda Lopes de Almeida, y A bolsa amarela, de Lygia Bojunga Nunes, es el objetivo de este artículo. El estudio abarca el periodo de 1919 a 1976 y, además de relacionar al personaje con el contexto histórico de producción de cada una de las narrativas, demuestra como la infancia es presentada en cada historia, a fin de reflexionar acerca del recorrido del niño como personaje en la literatura infantil brasileña. Finalmente, plantea que la literatura infantil además de ser texto artístico es fuente para la enseñanza de Historia en la Enseñanza Fundamental.

PALABRAS CLAVE: Narrativa infantil. Personaje. Historia de la literatura infantil brasileña. Enseñanza de Historia.

ABSTRACT: The objective of this article is to analyze the child character in five works: Saudade, by Tales de Andrade, Reinações de Narizinho, by Monteiro Lobato, A ilha

${ }^{1}$ Universidade de Caxias do Sul (UCS), Caxias do Sul - RS - Brasil. Professora, Área de Humanidades. ORCID: <https://orcid.org/0000-0002-1488-0534>. E-mail: ramos.fb@gmail.com

${ }^{2}$ Universidade de Caxias do Sul (UCS), Caxias do Sul - RS - Brasil. Professora, Área de Humanidades. ORCID: <https://orcid.org/0000-0001-9670-1634>. E-mail: nanirela@ gmail.com 
perdida, by Maria José Duprè, A fada que tinha idéias, by Fernanda Lopes de Almeida, and A bolsa amarela, by Lygia Bojunga Nunes. The study covers the period from 1919 to 1976 and, beyond relating the character to the historical context of production of each of the narratives, it shows how childhood is presented in each story, in order to reflect on the child's journey as a character in Brazilian literature for children. Finally, it discusses the idea that children's literature as well as being an artistic text is a source for the teaching of History in Elementary School.

KEYWORDS: Narrative for children. Character. History of Brazilian literature for children, Teaching History.

\section{Introdução}

A literatura infantil define-se a partir de seu destinatário: a criança, o que exige constante reflexão acerca da concepção de infância da sociedade. Se as discussões acerca do que é ser criança na história da sociedade ocidental têm se alastrado, o que dizer do modo como representar esse ser cuja identidade está em construção? Como ela é apresentada, já que é um outro, o adulto, que a configura? Analisar, nesse sentido, como a criança vem sendo representada em obras classificadas como literatura infantil é uma questão que se impõe. Outra questão é a valorização da literatura infantil como fonte para o ensino da História. O discurso indireto presente em narrativa da literatura infantil configura temporalidade, que pode ser utilizada como ponte entre as representações e o tempo fenomenológico. O uso didático desta no ensino de História pode ser uma brecha para o estudante, durante o Ensino Fundamental, acessar o universo cultural que oportuniza a construção de processos históricos como o das camadas populares da sociedade, como mudanças e permanências em contextos ambientais e em processos econômicos ou identitários.

Considerando as obras utilizadas neste estudo são evidenciadas possibilidades para aproximar o conhecimento histórico a temas do cotidiano, como por exemplo as noções de campo e de cidade; de modos de produção no Brasil sob aspectos dos setores agrícola e industrial; de lutas contra doenças, contra o latifúndio; de questões de gênero; de estrutura familiar; de religiosidade; de formas de governo, dentre outros.

Habitualmente, a história apresentada pelos livros didáticos entra na sala de aula com um caráter de verdade sobre o passado e não como uma das muitas versões sobre o que aconteceu. Assim, o processo de criação textual de uma narrativa concretiza a História, como também, a criação literária. 
No Brasil, o gênero literatura infantil é bastante jovem: conta com pouco mais de cem anos - aparece somente quando os pequenos têm um papel definido na família e na sociedade e há, mesmo que de modo incipiente, circulação de impressos. Como a narrativa é produzida para o leitor mirim, esse passa a ser um elemento constitutivo da obra, atuando, muitas vezes, como personagem, cuja construção evidencia, por seu turno, a concepção de criança da sociedade onde o texto se produz. Assim, a representação literária é um elemento determinante da condição ideológica da obra, conservadora ou emancipatória, o que interfere em seu estatuto estético.

Apoiada nessa hipótese, a presente investigação visa a discutir como a personagem infantil é construída em cinco obras da literatura infantil brasileira, abrangendo o período de 1919 a 1976, ou seja, de Tales de Andrade a Lygia Bojunga Nunes. Pretende-se ainda relacionar cada personagem ao contexto histórico de produção da narrativa, bem como realizar uma leitura diacrônica dos aspectos evidenciados nas diversas obras para a construção da personagem infantil.

A preferência por essas narrativas deve-se ao fato de Saudade (SA), de Tales de Andrade, editada em 1919, ser um dos primeiros livros, ambientado em cenário nacional, destinados aos escolares que têm como personagem central um menino; Reinações de Narizinho $(R N)$, de Monteiro Lobato, é uma coletânea de episódios revelados pelo autor a partir de A menina de nariz arrebitado, cuja primeira edição é de 1920; A ilha perdida (IP), de Maria José de Dupré, editada em 1946, expande o modelo lobatiano, conduzindo meninos urbanos a viverem uma aventura em uma ilha; $A$ fada que tinha ideias (FI), de Fernanda Lopes de Almeida, divulgada em 1971, traz uma visão de criança que rompe com o modelo comercial vigente até então; e $A$ bolsa amarela (BA), escrita por Lygia Bojunga Nunes e publicada em 1976, põe em cena as inquietações de uma menina, sob a ótica infantil. Trata-se, pois, de oito personagens infantis que mobilizam os enredos das obras, conforme evidencia o quadro 1.

Quadro 1 - Personagens infantis
\begin{tabular}{|l|l|c|}
\hline \multicolumn{1}{|c|}{ Personagens infantis } & \multicolumn{1}{|c|}{ Obra/Ano de edição } & Abreviatura das obras \\
\hline Mário e Rosinha & Saudade/1919 & SA \\
\hline Narizinho e Pedrinho & Reinações de Narizinho/1920 & RN \\
\hline Henrique e Eduardo & A ilha perdida/1946 & IP \\
\hline Clara Luz & A fada que tinha ideias/1971 & FI \\
\hline Raquel & A bolsa amarela/1976 & BA \\
\hline
\end{tabular}

Fonte: Elaboração própria 
A partir da representação da criança nessas narrativas, este artigo discute concepções de infância assumidas pela sociedade. Assim, serão enfocadas a individualidade da criança, sua inserção em grupos sociais e, por fim, o percurso da personagem infantil na narrativa, de forma a estabelecer relações diacrônicas que possibilitem perceber as alterações que sofre o conceito de infância no período.

\section{A individualidade da personagem criança}

A construção da personagem infantil nas obras destinadas aos pequenos leitores é uma forma de que a literatura dispõe para representar a criança. Dentre as cinco obras analisadas, quanto ao gênero, percebe-se que nas três primeiras a personagem masculina assume papel relevante: em $S A$ e $I P$, a ação é conduzida pelos meninos; em $R N$, ainda que o enfoque seja no elemento feminino, Pedrinho participa ativamente da ação. Nas outras duas narrativas, o destaque é dado ao feminino: em $F I$, o elemento masculino é totalmente suprimido do enredo; e em $B A$, o conflito mostra uma menina que tem o desejo de ser um garoto. Como se percebe, apenas em $R N$ há certo equilíbrio entre os gêneros.

Outro dado a ser salientado refere-se à idade das personagens infantis, que é explicitada na maioria das narrativas analisadas, ficando entre sete e catorze anos apenas em $B A$ não se define a idade de Raquel: sabe-se apenas que tem, em determinado momento da história, uma espinha na ponta do nariz, sugerindo estar na préadolescência. De qualquer maneira, a idade é indicada apenas como um traço na caracterização física da personagem.

Das cinco narrativas, percebe-se que algumas têm função predominantemente educativa, a fim de auxiliar a escola e a família na formação da criança. Em SA, são ressaltados "bons hábitos", essenciais para o futuro cidadão, como o respeito aos mais velhos e a humildade, dentre outros. Desde pequenos, os filhos são ensinados a auxiliar os pais: Rosinha ajuda na cozinha e no jardim; Mário é encarregado de ir ao açougue na cidade e também acompanha nhô Lau nas lides rurais. Clara, em FI, é incumbida de preparar bolinhos de luz, porque sua mãe tem que atender a outro compromisso. Os meninos Henrique e Eduardo, em IP, apesar de viverem peripécias no universo maravilhoso que é a ilha, continuam observando leis da civilização, como solidariedade e respeito. Raquel, em $B A$, questiona a cobrança de determinados comportamentos, como polidez no almoço na casa de tia Brunilda, humildade e subserviência em relação 
aos pais e irmãos, além do respeito ao horário na escola. $R N$, porém, foge a essa regra, pois Pedrinho e Narizinho, num ambiente em que quase tudo é permitido, questionam até mesmo Dona Benta, que exerce uma autoridade discreta no grupo.

Na maioria das narrativas, há, pois, a intenção explícita de educar o leitor. Diferenciam-se, porém, os métodos utilizados para isso: em $S A$, há apenas exaltação ao comportamento adulto; em $I P$, as iniciativas infantis que contrariam as determinações do adulto são punidas; já em $F I$, valoriza-se muito a iniciativa da criança; $R N$, por sua vez, respeita os questionamentos dos pequenos; e $B A$ mostra ao leitor uma alternativa para a solução de seus conflitos interiores.

Em relação à higiene, observa-se uma preocupação intensa ao referendar determinados hábitos de limpeza. Em $S A$, a organização existente no sítio é elogiada, bem como o capricho da empregada Tereza, que, pela convivência, possibilita o aos pequenos o aprendizado desses princípios. Em $R N$, a higiene surge de forma lúdica, sendo permitido a Pedrinho, por exemplo, após comer manga, permanecer com bigodes amarelos, levando-o a acreditar ser o Príncipe de Bigodes Amarelos; Narizinho deliciase com as jabuticabas saboreadas na planta, sem lavá-las, e tia Nastácia come a sardinha que cai na frigideira, mesmo sem ter sido limpa anteriormente.

Eduardo, Henrique e as demais crianças de $I P$, embora estejam em um ambiente em que é possível a vivência da fantasia, mantêm o hábito de lavar o rosto ao acordar, bem como escovar os dentes após as refeições. FI, no entanto, não faz menção à higiene, bem como $B A$, que não aponta aspectos relativos à limpeza de Raquel ou mesmo dos seres imaginários que povoam a narrativa.

Assim como a higiene não é evidenciada nessas duas obras, a saúde das crianças não é explorada pelos narradores dos cinco textos estudados, talvez porque tratam de universos idealizados, em que dificilmente alguém ficaria doente. Uma ressalva deve ser feita à $S A$ : Mário adoece em virtude da vida urbana, à qual não se adapta. Em $R N, \mathrm{o}$ médico interfere somente para dar à Emília o dom da fala. Em IP, há alusão ao estado um pouco debilitado de Eduardo, por ficar perdido na ilha. Já em $B A$, explora-se o equilíbrio psicológico da menina em conflito que, incompreendida pela família, busca entender e construir sua identidade.

Questões ligadas ao domínio psicológico da criança não são abordadas em obras anteriores à $B A$. Em $S A$, as crianças reproduzem os comportamentos dos adultos. Seus interesses são os mesmos dos mais velhos - até mesmo as brincadeiras introduzem os pequenos no universo adulto, numa atitude submissa, sugerindo-lhes temperamento 
dócil e cordato. Uma das distrações de Rosinha, em $S A$, é, por exemplo, cuidar do jardim, seguindo o exemplo da mãe, dona Emília, e de Tereza.

Em $R N$, o aspecto psicológico manifesta-se por atitudes que demonstram alegria, teimosia e iniciativa das crianças. Sentimentos negativos são também explorados, como a raiva. Destaca-se, ainda, a postura questionadora dos pequenos frente a obstáculos surgidos na concretização de determinado objetivo. As crianças são livres para realizar seus desejos; os adultos, por sua vez, não atuam como limitadores, ao contrário, dão espaço para que elas mesmas busquem alternativas que esclareçam suas dúvidas.

Eduardo e Henrique (IP), mesmo fugindo para a ilha no intuito de realizar desejo oculto, arrependem-se por terem desobedecido aos padrinhos. Os meninos são severamente punidos e só sobrevivem devido à interferência do adulto, seja na ilha seja no regresso à sede da fazenda. O narrador, por sua vez, centra-se nos aspectos físicos dos meninos, em detrimento aos psicológicos.

Em FI, Clara Luz é conhecida basicamente por suas ações. Ela manifesta-se como uma menina-fada, bastante autoritária, determinada e autêntica. Impõe as brincadeiras que distrairão as crianças e é responsável por profundas alterações no reino, como, por exemplo, a divisão de poder. A fadinha, tal qual as personagens infantis das outras narrativas (com exceção de Raquel), não questiona seu universo interior, preocupa-se, apenas, com elementos externos.

A caracterização da personagem criança, por sua vez, sofre transformações à medida que o tempo passa. Em $S A$, são elencados traços físicos que marcam a figura de Mário. Já em $R N$, as personagens são apresentadas basicamente por suas ações. Henrique, Eduardo e Clara Luz são configurados por suas ações, assim como as personagens de $R N$. Raquel, com a autoridade de narradora do texto, constrói sua figura e mostra-se ao leitor, priorizando sua subjetividade. Nesse sentido, pela análise diacrônica das personagens infantis, a descrição de aspectos físicos cede espaço para evidenciar a interioridade dos protagonistas.

\section{A criança enquanto ser social}

A criança possui determinados traços característicos ao seu ser e que compõem a sua individualidade. Porém, além desses elementos, há outros que auxiliam na construção da personagem infantil enquanto ser social, inserindo-a seja na família, na 
escola ou na comunidade, além de explorar aspectos como religiosidade, vestimenta, alimentação, presentes na vida de qualquer sujeito.

As personagens infantis, nessas obras, estão inseridas em uma estrutura familiar. No caso de $S A$, a família é composta pela figura do pai, da mãe, dos filhos e dos empregados domésticos. Nessa narrativa, o narrador adulto enfoca o coleguismo existente entre os pequenos do mesmo sexo. Em $R N$, as figuras paterna e materna estão ausentes - a autoridade é exercida por dona Benta, a avó, e tia Nastácia, a cozinheira. As crianças convivem com animais e figuras pertencentes a obras clássicas da literatura universal. A relação entre irmãos é ignorada - Narizinho e Pedrinho são primos. Os pais estão ausentes, também, em $I P$, sendo esse papel desempenhado pelos padrinhos dos meninos. Apesar da presença de amigos da mesma idade, tanto meninos quanto meninas, o narrador não explora a sexualidade entre as crianças, tampouco a amizade entre os pequenos.

A família de Clara Luz é formada apenas pela fadinha e sua mãe. Não há elementos masculinos, exceto senhor Relâmpago e Relampinho. A mãe de Clara, no geral, defende a filha de possíveis complicações em que a fadinha possa se envolver. Ignora-se, na narrativa, a figura paterna, bem como as relações entre crianças de sexo oposto e mesmo entre irmãos. Raquel, inserida num grupo formado pelos pais, uma irmã e um irmão mais velho, enfrenta problemas na convivência com os familiares. A narrativa avança na medida em que questiona a relação da menina consigo mesma, com os membros de sua família e com os demais seres que compõem a narrativa. Após considerar a estrutura familiar da menina como falida, é apresentado outro quadro, o dos moradores da Casa dos Consertos, onde predomina a democracia, havendo discussões acerca de decisões a serem tomadas, bem como propostas de alteração de papéis familiares.

Em cada uma das estruturas presentes nos títulos, a criança ocupa um papel diferenciado. É o que ocorre com Mário e Rosinha, que atuam como pequenos adultos, pois reproduzem o comportamento dos pais, não questionam os mais velhos e não os desobedecem; caso não cumpram alguma ordem, sentem-se culpados. Pedrinho e Narizinho, por outro lado, não seguem parâmetros indicados por adultos, até porque estes deixam os pequenos livres para agir - desejam, apenas, que sejam bondosos.

As crianças lobatianas, interferindo na estrutura familiar, chegam mesmo a convencer a avó a participar de uma aventura, conduzindo-a, pela imaginação, às terras das Mil e uma noites. Henrique e Eduardo, longe dos pais, recebem ordens dos 
padrinhos, o que ameniza o papel de autoridade. Mesmo assim, desafiam leis impostas, indo até a ilha perdida. A desobediência ao adulto implica, nesse caso, punição, pois ficam abandonados e só sobrevivem e regressam à fazenda graças ao auxílio dos mais velhos.

Clara Luz, ao contrário, é quem conduz a história e provoca mudanças na sua mãe e, posteriormente, nos demais habitantes do reino, exercendo um papel ativo. Já Raquel é marginalizada pelos familiares, pois não consegue estabelecer cumplicidade com seus irmãos e nem mesmo com seus pais. Para compensar a ausência de relação afetiva, cria amigos imaginários, com os quais se corresponde e, mais tarde, inclusive, traz alguns para seu universo interior, representado pela bolsa amarela. É Raquel, no entanto, quem conduz a narrativa como protagonista e narradora.

Além das relações familiares, a análise observa questões socioculturais, pela interação ou não dos pequenos com outras instituições. Assim, na maioria dos casos, além de as crianças pertencerem a uma família, estão inseridas na sociedade, constituída pela vizinhança, pela escola, pela comunidade religiosa e governamental.

Em SA, a escola ocupa lugar privilegiado; as crianças, antes mesmo de ingressarem no educandário, já têm o seu universo ampliado, pois fazem parte de um grupo de vizinhos, são levadas à escola pelo pai e lá devem sempre obedecer à dona Alzira, vista como uma senhora muito bondosa, tanto pelos pais como pelos alunos. $\mathrm{O}$ ambiente de aprendizagem escolar, apesar da ausência da instituição formal, está presente também em $R N$. Dona Benta, pelos livros, possibilita o acesso ao conhecimento para seus netos, além de oportunizar-lhes vazão à imaginação. Em IP, como em $R N$, as crianças estão em férias e ausentes da escola, sendo que, na primeira obra, a aprendizagem não é algo que faça parte do cotidiano infantil.

Clara Luz, por sua vez, revoluciona a concepção de escola em seu reino, questionando o ensino, sempre repetitivo, ministrado pelos professores. Ela convence a mestra a mudar sua prática educativa, criando situações de aprendizagem a partir da realidade e da experiência. Já Raquel critica a rigidez do horário e a impossibilidade de concluir o texto que tanto a empolga, mas não sugere alternativas de mudança à instituição. A escola é um valor da sociedade contemporânea e, como tal, é representada nas narrativas. Mais recentemente, sua estrutura vem sendo questionada, o que é perceptível nas posturas de Clara Luz e Raquel.

A vizinhança geralmente desempenha importante papel. Mário, Rosinha e seus pais convivem, harmonicamente, com os vizinhos, num clima de ajuda mútua. O sítio 
do Picapau Amarelo é praticamente autossuficiente, recebendo apenas livros e outros materiais que ali não são produzidos; o sítio, porém, acolhe visitantes oriundos de outras narrativas clássicas, como Pequeno Polegar, Bela Adormecida, Cinderela e outros. Clara e sua mãe mantêm boas relações com a vizinhança, - todos são convidados a participar de festividades e auxiliam na resolução de problemas que, por ventura, surjam. Raquel mantém convivência pacífica com outras pessoas, principalmente com os moradores da Casa dos Consertos. No entanto, a menina, magoada, reage contra a família de tia Brunilda, porque seus pais e irmãos bajulam a parenta abastada em virtude de presentes recebidos. Percebe-se, assim, o envolvimento da vizinhança em $S A$, IP e FI, mas em $R N$, talvez pela quase autossuficiência do sítio, e em $B A$, pelo tom subjetivo impresso aos conflitos da protagonista, essa questão não é explorada.

A religiosidade, presente em alguns enredos, como em $S A$, por exemplo, reforça a ideia de princípios doutrinários que devem ser respeitados pelos pequenos desde cedo, como obediência, respeito e humildade. Em $R N$, não há alusão a um ser espiritual que deva ser respeitado. Mas os meninos de IP, Henrique e Eduardo, sentindo-se perdidos, invocam a Deus e a Nossa Senhora para salvá-los, rezando baixinho. Assim como em $R N$, os textos mais recentes, $F I$ e $B A$, não fazem qualquer referência à religiosidade das personagens infantis. O sentimento religioso não é, pois, uma marca constante das personagens infantis e, quando tratado, aparece de forma sutil.

Instituições mais abrangentes, como o Governo, estão presentes no corpus analisado. Em $S A$, ele é visto com uma função paternal, ou seja, orienta e auxilia as famílias. Por iniciativa governamental, através do incentivo e apoio dado aos agricultores, as famílias que fazem de suas terras uma pequena empresa, prosperam. Seu Raimundo, pai de Mário, por exemplo, havia abandonado a vida no sítio, mas retorna e aplica orientações técnicas fornecidas pelo Governo - inclusive, atendendo a um chamado de melhor conviver com os bens naturais, o menino estuda Agronomia. Narizinho e Pedrinho vivem num microcosmo isolado da comunidade em geral. Nesse meio, criam suas próprias leis, à revelia de possíveis determinações do Estado. A única autoridade existente no Sítio é exercida democraticamente pela avó e por tia Nastácia. Já no universo ficcional de $I P$ - uma ilha do rio Paraíba - não há referência a nenhum auxílio ou órgão governamental. Para salvar os meninos, quem se mobiliza são os moradores próximos da fazenda do padrinho, não havendo menção do papel do Governo na história, ou seja, a comunidade cria alternativas para resolver os conflitos vividos. 
O contrário ocorre em $F I$, pois Clara Luz altera, por sua determinação e questionamento, toda a estrutura de poder autoritário exercido pela Rainha. O autoritarismo, que apavora os moradores do reino, é substituído por uma administração equilibrada das ações a serem realizadas. A criança, na nova estrutura, exerce papel fundamental, pois Clara, além de questionar o poder existente, participa da nova gestão do reino como conselheira-chefe da Rainha. $\mathrm{O}$ autoritarismo está presente em $B A$, seja na família de Raquel, em relação à tia Brunilda ou entre os galos Afonso e Terrível e seus donos. No entanto, é tratado considerando seus reflexos para os conflitos interiores das personagens e não apenas na exploração de aspectos externos. A abordagem de questões governamentais é, assim, concretizada sob formas diferenciadas nas cinco obras em questão, revelando posturas de aceitação, alienação, questionamento e indiferença.

A respeito de produções culturais, percebe-se que Mário, em $S A$, lê revistas, endereçadas ao pai, que versam sobre agricultura. $\mathrm{O}$ menino também cria um cinema, a fim de distrair seus companheiros. Rosinha, por sua vez, não entra em contato com as revistas lidas pelo irmão. Narizinho e Pedrinho, em contrapartida, escutam, frequentemente, histórias clássicas narradas pela avó - dona Benta lê de uma forma diferente, pois atualiza termos arcaicos, como também traduz palavras portuguesas por sinônimos brasileiros. Henrique e Eduardo, isolados da civilização, não têm contato com produções culturais como livros ou filmes. O balé de Clara Luz, em FI, é idealizado e produzido pela menina, a partir de elementos disponíveis no universo ficcional, a fim de distrair os moradores da Via Láctea e demais convidados.

Raquel, de $B A$, deseja ser escritora e, por isso, cria diversas histórias que se encaixam na narrativa-primeira, as quais lhe causam problemas ao serem descobertas pelos adultos. Seus questionamentos não se limitam à sua faixa etária: ela também defende que os seus desejos devem ser respeitados, mas não elabora nenhum questionamento sobre produtos que lhe são destinados, exceto as roupas. Entende-se, assim, que apenas em $R N$ evidencia-se a manifestação da existência de produtos culturais específicos à criança - são histórias que, pela intervenção de dona Benta, são adequadas ao pensamento infantil, ao contrário de $S A$, em que não há uma literatura específica para criança, reforçando a ideia de que o comportamento infantil repete atitudes do adulto. 


\section{$O$ percurso da personagem infantil na narrativa}

A representação da criança na narrativa, seja por seu aspecto físico ou psicológico, familiar ou social, lúdico ou crítico, é condicionada aos interesses do narrador com relação ao espaço da personagem na história, sem deixar de considerar a temática do texto que está sendo construído. Assim, em $S A$, por se tratar de uma reconstrução a partir das lembranças da infância do menino, é a memória seletiva de Mário que elabora o enredo, ou seja, é de uma narrativa em primeira pessoa, em que a criança é também testemunha da ação. Em $B A$, a menina Raquel atua, a exemplo de Mário, como um narrador autodiegético, mas com uma diferença fundamental: ela ainda é uma criança e, portanto, enuncia conflitos infantis, ao contrário de Mário, que relata os fatos com uma visão adulta. Mesmo ciente de que o narrador é uma figura de papel criada no universo ficcional da narrativa que não se confunde com o autor de uma obra, cabe nesta reflexão trazer alguns pontos atinentes à figura do autor, sujeito social que viveu em determinado contexto e tempo histórico.

Tales de Andrade, em $S A$, ao eleger a memória seletiva do personagem Mário, abre uma janela para lembrar marcas de um passado, modelando fenômenos, evidenciando mudanças e também um desejo de permanência de hábitos, evitando assim rupturas históricas na sociedade nacional.

O autor nasce no primeiro ano da República brasileira - 1890 -. Professor por profissão, ministrou aulas de História Geral e também do Brasil. Sua formação e os anos iniciais de magistério se dão em um contexto de desorganização econômica devido à profunda modificação no modo de produção nacional. Ele vive no tempo histórico em que o modo de produção escravista lentamente será substituído pelo trabalho livre e assalariado, cuja transição significa também rupturas nas estruturas sociais centradas na vida rural por mais de 3 séculos. A jogatina na Bolsa promove cotidianamente fortunas e também falências, conferindo novo tom para o processo de urbanização, o que implica, no momento, uma relação de forças entre classes sociais e suas propostas de Nação para o Brasil.

A estrutura urbana do período colonial, em alguns centros, é remodelada com largas avenidas, ocasionando a remoção de famílias pobres moradoras em zonas centrais para espaços afastados e inserindo um novo som, o dos motores dos veículos. O episódio da Revolta da Vacina, ocorrido no ano de 1904, no Rio de Janeiro, é exemplo da reação popular à remoção. E em 1908, por ocasião do centenário da abertura dos 
portos às nações amigas, um bonde com motor no lugar da tração animal transporta pessoas, em caráter experimental.

Nas décadas iniciais da República há evidencias de combate às tradições culturais de origem africana. Segundo Del Priore (2017, p. 21), o Código Penal de 1890 condenava várias formas de religiosidade e, também, o jogo da capoeira. A medicina, por sua vez, criticava os hábitos alimentares advindos de tais tradições.

O professor, alfabetizador e escritor Tales de Andrade modela seu pensamento em tal contexto e faz a opção literária por escrever para crianças moradoras do campo. Temas como ensino, agricultura, hábitos da vida rural, processos de urbanização como ameaça à vida no campo fazem parte de seus escritos, como evidenciado em $S A$. A menina que auxilia na cozinha e no jardim; o menino que vai ao açougue e participa nas atividades rurais; o personagem Mário que adoece por não se adaptar à vida urbana são alguns indicativos da concepção de sociedade posta pelo autor. O ruralismo carrega a ideia de uma nação predominantemente agrícola. A narrativa presente em $S A$ torna-se uma fonte histórica rica, potente, uma vez que traduz uma percepção possível do futuro da Nação, dentre outras presentes no texto literário de outros autores, como será o caso de Monteiro Lobato.

As peripécias de Pedrinho e Narizinho, Eduardo e Henrique, bem como de Clara, são narradas por sujeitos externos aos universos diegéticos dessas personagens; em cada um dos textos, encontram-se narradores heterodiegéticos. No caso de $I P$, a visão do narrador é adultocêntrica, sendo que a personagem infantil é apenas um elemento a ser manipulado, a fim de comprovar a dependência da criança com relação ao adulto. Em $R N$, o narrador respeita as decisões das personagens infantis, às quais é dado o direito de problematizar e apontar soluções às várias situações vividas. Em FI, observa-se que a personagem infantil é mais autoritária que o próprio narrador. Clara determina as ações de todas as personagens, conduzindo o conflito e indicando soluções.

Mário, Henrique e Eduardo são conduzidos por narradores adultocêntricos que punem as crianças por suas desobediências, mostrando-lhes que o fato de não seguirem as prescrições determinadas pelos mais velhos acarreta situações desagradáveis. Pedrinho e Narizinho, representações da infância lobatiana, surpreendentemente têm seus anseios respeitados e garantidos pela fantasia. Raquel, como narradora do texto, inaugura uma nova tendência na literatura infantil brasileira, que passa a explorar a interioridade da criança. Mário, ainda que seja o narrador da história, salienta o respeito 
ao adulto, até porque se manifesta como voz adulta a relembrar o passado. O narrador, ao relatar as ações de Mário ( $S A)$, não parece preocupado com elementos estéticos e valores éticos de respeito e aceitação. A aridez estética torna-se mais evidente ao se constatar a presença de dados realísticos, que dificultam o desenvolvimento da imaginação infantil e anulam a fantasia.

Os elementos mágicos são componentes importantes nos textos destinados ao público infantil. Não é por acaso que os contos maravilhosos, devido à sua estrutura e à presença de elementos mágicos, tornam-se material de leitura das crianças. Ignorar a fantasia em um texto destinado ao leitor mirim é gerar uma obra fadada ao esquecimento. SA é um título desconhecido na atualidade pelo público infanto-juvenil, visto que não dialoga com os anseios do leitor contemporâneo.

As demais obras ainda estão presentes em catálogos de editoras e nos acervos de bibliotecas escolares, talvez pela presença da magia e pela atualidade dos temas abordados. Narizinho e Pedrinho instauram no sítio um universo mágico, no qual impera o ilogismo. Além disso, essa narrativa explora a intertextualidade, trazendo para a história inicial personagens como dona Carochinha, Peter Pan, Bela Adormecida, Cinderela e outras, dinamizando ainda mais o enredo.

Narizinho e Pedrinho são personagens que Monteiro Lobato criou com o espírito de crianças que deveriam construir a futura nação. Contemporâneo de Tales de Andrade, conviveu com o mesmo contexto nacional e mundial. Recém terminados os conflitos da Primeira Guerra Mundial, o sentimento de nacionalismo estava em voga e era a palavra do momento. A participação do Brasil no conflito se dá a partir de 1917. A efervescência política chegava em território nacional em especial por meio de periódicos. Temas como nacionalidade e identidade são discutidos por diferentes grupos de intelectuais. Lobato, engajado em tais discussões, defende para a nação um futuro amparado na cientificidade, na modernização dos centros urbanos, na implementação do saneamento básico, na industrialização, enfim, defendia um futuro diferente do vivido pela sociedade brasileira até então. As concepções de sociedade e de cidadão, defendidas pelo escritor, são diferentes, pode-se dizer até opostas, às concepções defendidas por Tales de Andrade.

Problemas abordados em $R N$ como quem é o trabalhador; qual o papel das oligarquias, as diferenças étnicas, atuam como provocações instigadoras à reflexão dos padrões sociais, políticos, culturais e econômicos vigentes. Santos (2008, p. 23) registra que as crianças são mentes questionadoras necessárias ao projeto de nação. Narizinho 
representa a ética feminina na proposta de nação; Emília incorpora o papel da transgressão; Pedrinho representa o empreendedor prático necessário ao futuro da nação, e Lobato possibilita a criança agir livremente, a fim de construir um "modelo" capaz de operar a invenção deste "Sítio/Brasil" (lugar onde sempre existirá ciência).

A concepção de infância proposta em $R N$ contrapõe-se à infância vivenciada até as primeiras décadas da República, evidenciando contrastes entre os filhos dos senhores abastados e os outros infantes. Os primeiros viviam uma infância cercada pelas famílias e as experiências vividas em comum, na posição dentro dos laços de filiação, nas regras de funcionamento familiar, nas trajetórias dos costumes e saberes técnicos (DEL PRIORE, 2017, p. 409). Os outros são os filhos da classe pobre, os órfãos, os abandonados, para os quais infância é sinônimo de obrigações, de trabalho. Com tal contexto, o senso realizado no ano de 1920 indicou o índice de 69,9\% de analfabetos considerando-se a população de quinze anos ou mais (FAUSTO, 2000 p. 393). Os personagens infantis de $R N$ são protagonistas de suas histórias, e propõem uma outra forma de funcionamento para a sociedade e a nação.

Apesar da censura velada do adulto, IP continua sendo lida, pois a aventura permeia o enredo. A criança tem a iniciativa de ir até a ilha, mas não sobrevive, nem regressa, sem o auxílio dos adultos. Mesmo assim, o clima de fantasia está presente na ilha, espaço mágico onde as crianças se perdem. Evidencia-se, então, que é possível sonhar apenas quando as crianças estão sós; o adulto é configurado como um sujeito fiscalizador, que explora a racionalidade, escondendo aspectos imagísticos. No caso de $I P$, a visão do narrador é adultocêntrica, sendo que a personagem infantil é apenas um elemento a ser manipulado, a fim de comprovar a dependência da criança com relação ao adulto.

A publicação de $I P$, por Dupré, ocorre logo após o término do período de 15 anos do governo de Getúlio Vargas como presidente do Brasil. Com o uso intensivo dos meios de comunicação, durante o período, ocorre a construção da imagem de Getúlio como protetor dos trabalhadores e guia dos brasileiros. Figura centralizadora, procurou conciliar interesses entre os diferente grupos sociais, a fim de promover mudanças necessárias com o menor risco possível para geração de conflitos. Conciliação de interesses, centralização de poderes e intervenção do Estado foram marcas identitárias do período.

É possível identificar características do contexto nos cenários da história e comportamentos das crianças protagonistas da aventura. A conciliação entre a sociedade 
urbana e a rural pode ser identificada nos meninos urbanos que passam férias na fazenda dos padrinhos. Durante o planejamento e a execução da aventura não há conflito, e as ideias diferentes são negociadas.

A narrativa contém intenções pedagógicas para a transmissão de normas. Uma delas é a família evidenciada em passagens como o conforto proporcionado pelo espaço familiar e o compromisso que os meninos manifestam com os membros que dela fazem parte. A nação em construção precisa de um modelo social no qual o adulto é exemplo de como agir em sociedade, orientando os jovens para o bom caminho. Tanto uma norma quanto outra remetem àquela imagem do presidente como guia e como exemplo. A punição, quando ocorre desobediência, faz refletir sobre o Estado que intervém, não somente nas questões públicas, mas também no âmbito privado.

Em FI, as ações se desenvolvem no espaço mágico da Via Láctea, e as personagens como fadas e bruxas alimentam a fantasia nos capítulos iniciais da obra. Mais tarde, contudo, esses elementos são abandonados por Clara, que conduz as ações, interferindo na administração do reino de modo realístico.

Quando Fernanda Lopes de Almeida publica FI, o Brasil estava no quinto ano com os militares no governo. A educação nacional passava pela reformulação do Ensino Superior, com ampla privatização da escolarização em todos os níveis. O País vivia também a adaptação do $1^{\circ}$ e $2^{\circ}$ graus, sendo este profissional, o que evitaria a busca pelo ensino superior. As reformas implementaram educação com forte viés tecnicista. Mas talvez a consequência mais imediata ocorreu na representação estudantil. Proibida a atuação das diferentes organizações desde 1967, as representações estudantis das escolas foram transformadas em centros cívicos. Com a ausência de espaços para discussões políticas, enfraquecimento das disciplinas da área de Humanas, a juventude brasileira passará por um longo período de silenciamento, o qual será garantido pelo Ato Institucional $\mathrm{n}^{\circ} 5$ (AI-5). O documento retirou garantias individuais, públicas ou privadas.

A personagem Clara Luz enuncia os contrapontos ao contexto do momento: para a reforma tecnicista ela revoluciona a concepção de escola em seu reino, questionando a mesmice que estava em prática; para o silenciamento imposto por força de lei, ela questiona constantemente; para a centralização de poder nas mãos do presidente militar, ela será responsável pela divisão de poderes no reino; para o autoritarismo, ela o substitui por uma administração equilibrada das ações a serem realizadas. A 
protagonista atua, pode-se dizer, como elemento pedagógico provocador de questionamentos sobre instituições e conjunturas sociais.

Já o universo que compõe $B A$ é totalmente mágico. Os amigos de Raquel são seres imaginários e atuam como projeções das vontades da menina. Tem-se uma narrativa de moldura, de modo que dentro da ficção primeira, são inseridas outras histórias que a ela se encaixam. Sem preocupação com a linearidade, o texto é construído, a exemplo da mente infantil, abrindo-se a outras questões que vão surgindo e ali podem se desenvolver.

A produção de Lygia Bojunga em $B A$, entretanto, ultrapassa os limites da fantasia, colocando em jogo questões essenciais à conjuntura vivida pelos jovens contemporâneos daquele contexto. Raquel, a criança protagonista, coloca em movimento críticas à sociedade dos anos 1970, que, no Brasil, andava de mãos dadas com concepções conservadoras, o que a leva esconder seus três grandes desejos na bolsa. A realidade social e histórica faz parte do cotidiano da menina, de seus questionamentos, de seus desejos.

O sentir-se oprimida remete ao contexto social regulado pela censura que ganha reforço com o galo, cujo pensamento estava costurado. Questionar a subserviência em relação aos pais e irmãos indica uma característica vivenciada pelos jovens naqueles anos, diga-se os mais duros do período militar. Ao considerar falida a estrutura familiar, opina sobre o próprio modelo da estrutura da pátria nacional.

E a Bolsa Amarela? Bem, essa é o próprio espaço interior, no qual há liberdade para organizar a "sociedade" segundo suas concepções; onde os diferentes convivem; onde a democracia é possível. Na última obra estudada, os conflitos internos vão sendo solucionados pela imaginação e pela criação de outras histórias que resolvem pendências iniciais. É, pois, pela fantasia que são solucionadas as inquietações dos pequenos. A fantasia surge como um elemento capaz de contribuir para solucionar as limitações impostas pelo ambiente opressor onde as personagens infantis estão inseridas.

Considerando os personagens estudados nas obras indicadas neste estudo, o percurso da criança como personagem na literatura infantil dá pistas sobre as concepções políticas de cada autor, sobre o projeto de cidadão almejado, sobre a forma de Estado vigente (contestando-o ou referendando-o). Andrade escreve $S A$ em meio ao contexto de transição da sociedade rural para urbana, assim apresenta crianças em comunhão com o contexto rural. Lobato, ao apresentar crianças com autonomia em seus 
pensamentos e atitudes defende a formação de cidadãos adeptos ao processo de industrialização. A seu tempo, Dupré idealiza crianças conciliadoras conforme o líder da Nação, enquanto Almeida e Bojunga incentivam as crianças ao pensamento crítico, com espírito democrático e não subserviente.

As obras, para além de objeto literário que encanta, são fontes históricas para o estudo das diferentes concepções de educação do espírito infantil e dos processos culturais que circundaram os projetos de cidadania para a Nação. Tratam-se, pois, de peças que ao integrarem o currículo escolar contribuem para alargar tanto as vivências estéticas como também o entendimento acerca do universo social e cultural do seu país.

AGRADECIMENTOS: CNPq - Processo: 305191/2016-0 Demanda/Chamada: Chamada CNPq N ${ }^{\circ}$ 12/2016 - Bolsas de Produtividade em Pesquisa - PQ

\section{REFERÊNCIAS}

ALMEIDA, Fernanda Lopes. A fada que tinha idéias. 20 ed. São Paulo: Ática, 1993.

ANDRADE, Tales de. Saudade. 52 ed. São Paulo: Companhia Editora Nacional, s/d.

DEL PRIORE, Mary. História da gente brasileira. Vol. 3 República - Memórias (1889 - 1950). Rio de Janeiro: LeYa, 20017.

DUPRÉ, Maria José de. A ilha perdida. 28 ed. São Paulo: Ática, 1992.

FAUSTO, Boris. História do Brasil. 8 ed. São Paulo: Edusp e FDE, 2000.

LOBATO, Monteiro. Reinações de Narizinho. 47 ed. São Paulo: Brasiliense, 1993.

NUNES, Lygia Bojunga. A bolsa amarela. 22 ed. Rio de Janeiro: Agir, 1993.

SANTOS, Elisângela da Silva. Monteiro Lobato e suas seis personagens em busca da nação. 2008. 144 f. Dissertação - Universidade Estadual Paulista, Marília, 2008.

\section{Como citar este artigo:}

BROCCHETTO RAMOS, Flávia.; RELA, Eliana. A infância na narrativa infantil brasileira: de Mário a Raquel. Revista Ibero-Americana de Estudos em Educação, Araraquara, v. 13, n. 4, p. 1742-1758, out./dez., 2018. E-ISSN: 1982-5587. DOI: 10.21723/riaee.unesp.v13.n4.out/dez.2018.11152 